\title{
Analysis of gravity waves from radio occultation measurements
}

\author{
M. Lange und Ch. Jacobi
}

\begin{abstract}
In the height range $10-30 \mathrm{~km}$ atmospheric gravity waves lead to periodic perturbations of the background temperature field in the order of 2-3 K, that are resolved in temperature profiles derived from radio occultation measurements. Due to the spherical symmetry assumption in the retrieval algorithm and the low horizontal resolution of the measurement damping in the amplitude and phase shift of the waves occurs leading to remarkable errors in the retrieved temperatures. The influence of the geometric wave parameters and the measurement geometry on plane gravity waves in the range $100-1000 \mathrm{~km}$ horizontal and $1-10 \mathrm{~km}$ vertical wavelength is investigated with a $2 \mathrm{D}$ model ranging $\pm 1000 \mathrm{~km}$ around the tangent point and $10-50 \mathrm{~km}$ in height. The investigation shows, that with radio occultation measurements more than $90 \%$ of the simulated waves can be resolved and more than 50\% with amplitudes above $90 \%$. But the geometrical parameters cannot be identified, since one signal can be attributed to different combinations of wave parameters and view angle. Even short waves with horizontal wavelengths below $200 \mathrm{~km}$ can be derived correctly in amplitude and phase if the vertical tilt is small or the view angle of the receiver satellite is in direction of the wave crests.
\end{abstract}

\section{Zusammenfassung}

Atmosphärische Schwerewellen führen im Höhenbereich $10-30 \mathrm{~km}$ zu periodischen Störungen des Hintergrundtemperaturfeldes in der Größenordnung von 2-3 K, die in Temperaturprofilen aus Radiookkultationsmessungen aufgelöst werden. Aufgrund der sphärischen Symmetrieannahme im Retrievalverfahren und durch die niedrige horizontale Auflösung des Messverfahrens werden Phasenverschiebungen und Dämpfung der Amplitude verursacht, die zu beachtlichen Fehlern bei den abgeleiteten Temperaturen führen. Der Einfluss der geometrischen Wellenparameter und der Messgeometrie auf ebene Schwerewellen im Bereich 100-1000 km horizontale und 1-10 km vertikale Wellenlänge wird untersucht mit einem 2D-Modell, dass sich auf ein Gebiet von $\pm 1000 \mathrm{~km}$ um den Tangentenpunkt und von $10-50 \mathrm{~km}$ in der Höhe erstreckt. Die Untersuchung zeigt, dass mit Radiookkultationsmessungen mehr als $90 \%$ der simulierten Wellen aufgelöst werden und mehr als 50\% mit Amplituden oberhalb von 90\% der ursprünglichen. Die geometrischen Parameter können jedoch nicht aus Einzelmessungen abgeleitet werden, da ein Signal zu verschiedenen Kombinationen von Wellenparametern und Sichtwinkel zugeordnet werden kann. Auch relativ kurze Wellen mit horizontalen Wellenlängen unterhalb von 200 km können korrekt in der Amplitude und Phase aufgelöst werden, falls die Neigung des Wellenvektors gegen die vertikale gering ist oder der Sichtwinkel des Empfängersatelliten in Richtung der Wellenberge ist.

\section{Introduction:}

Gravity waves play a main role in the circulation of the middle atmosphere. GPS radio occultation (RO) measurements provide a new tool to estimate gravity wave activity on a global data base (Tsuda et al., 2000). Unfortunately, due to the low horizontal resolution of about 200-400 km (Kursinski et al., 1997) and the spherical symmetry assumption in the retrieval algorithm for atmospheric parameters, damping of the amplitude and phase shift in the derived temperature profiles occur depending on the gravity wave parameters. Short scale waves with horizontal wavelengths below 50-100 km are filtered out due to the averaging over positive and negative phase variations of the GPS Signal, whereas large-scale waves with horizontal wavelengths above $1000 \mathrm{~km}$ fit to the spherical symmetry assumption (Belloul and 
Hauchecorne, 1997). Therefore the vertical profiles of small gravity waves cannot be derived directly, and the potential energy derived from the temperature variance used to describe climatologies of gravity wave activity is estimated too low.

The task of this study is to investigate what kind of plane gravity waves can be derived from temperature profiles of radio occultations. The question what is seen by the GPS receiver of the low earth orbiter (LEO) satellite is investigated by applying the inversion technique on excess path delays introduced by simulated gravity wave fields in an isothermal atmosphere in dependence from the geometric parameters of the waves and the view angle of the satellite through the wave. Following the approach of Preusse et al. (2001), who derived gravity waves from simulations of the LIMB sounding technique of optical thin layer radiation with the CRISTA instrument, a two dimensional model is used to describe the wave structures scanned during occultation. The model domain ranges $\pm 1000 \mathrm{~km}$ around the tangent point and covers the height range of 10-50 km. Ionospheric effects are not considered here and the influence of the upper part of the atmosphere is neglected due to the low density. This is in correspondence with usual temperature retrievals, that use upper boundary temperatures from external analysis at about $60 \mathrm{~km}$ (Hocke, 1997). The considered gravity wave spectra are characterized by $\lambda_{\mathrm{x}}=100-1000 \mathrm{~km}$ and $\lambda_{\mathrm{z}}=1-10 \mathrm{~km}$.

\section{Retrieval of temperature variations from gravity waves}

To derive temperature profiles of the gravity wave from excess path delay measurements perturbation equations are calculated. Therefore the atmospheric delay $\phi_{1}$ is divided in a mean atmospheric part and the wave part $\Delta \phi_{1}$. Following the approach of Fjeldbo and Eshleman (1965) the corresponding perturbation of the refractive index $\Delta \mathrm{n}$ may be written:

$$
\Delta \mathrm{n}(\mathrm{r})=-\lambda / \pi \sqrt{\Delta \mathrm{r} / 2 \mathrm{r}} \mathrm{d} \Delta \Phi_{1} / \mathrm{dr}+\lambda / \pi \int_{\mathrm{r}+\Delta \mathrm{r}}^{\infty}\left(\Delta \Phi_{1}(\mathrm{r})-\Delta \Phi_{1}(\xi)\right)\left(\xi^{2}-\mathrm{r}^{2}\right)^{-3 / 2} \xi \mathrm{d} \xi
$$

Here $\lambda$ denotes the wavelength of the GPS signal, $r$ the distance of the tangent point from earths center and $\xi$ the integration variable. Assuming small perturbations compared to the mean values, the ideal gas law and a dry atmosphere, the perturbation equations for the atmospheric parameters are expressed as follows:

$\Delta \mathrm{N}=10^{6} \Delta \mathrm{n}=\mathrm{k}_{1} * \mathrm{R} * \Delta \rho$

$\Delta \mathrm{r}=-\mathrm{p}_{0} /\left(\mathrm{RT}_{0}\right) * \Delta \mathrm{T} / \mathrm{T}_{0}+\Delta \mathrm{p} /\left(\mathrm{RT}_{0}\right)$.

$\mathrm{R}$ is the gas constant, $\mathrm{k}_{1}=77.6 \mathrm{~K} / \mathrm{hPa}$ is a proportionality factor, $\mathrm{T}_{0}$ and $\mathrm{p}_{0}$ represent the temperature and pressure of the undisturbed atmosphere and $\Delta \mathrm{N}$ denotes the refractivity. Assuming adiabatic conditions the pressure variation may be expressed by the temperature disturbance and the temperature signal becomes directly related to the refractivity

$\Delta \mathrm{p}=7 / 2 \mathrm{p}_{0} \Delta \mathrm{T} / \mathrm{T}_{0}$ $\Delta \mathrm{T}=1 / \mathrm{k}_{1} 2 / 5 \Delta \mathrm{NT}_{0}^{2} / \mathrm{p}_{0}$ 


\section{Model setup}

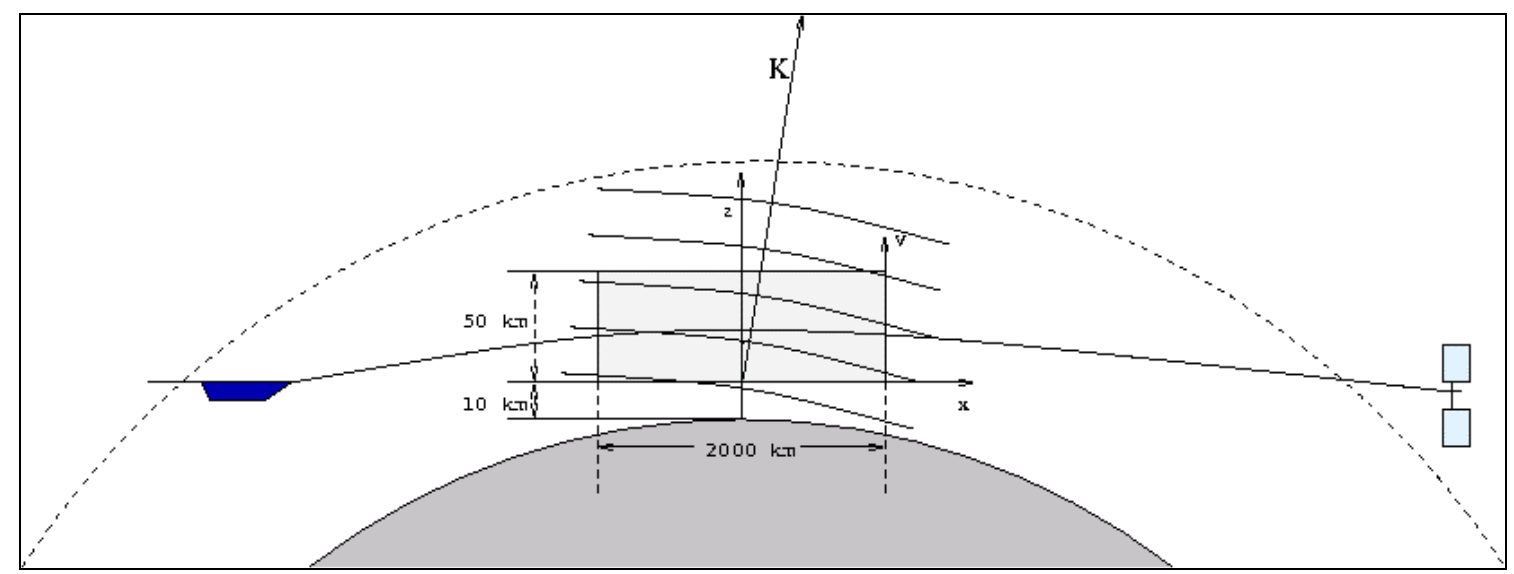

Figure 1: Measurement geometry of the occultation. The model domain covers a horizontal range of $2000 \mathrm{~km}$ and extends from 10 to $50 \mathrm{~km}$ in the vertical. For a better view the vertical scale is exaggerated.

\section{Model description}

\begin{tabular}{|l|l|}
\hline 2D Model: & $2000 \mathrm{~km} \times 40 \mathrm{~km}$ \\
\hline Range: & $\mathrm{x}=-1000-1000 \mathrm{~km}$ around the tangent point, $\mathrm{y}=10-50 \mathrm{~km}$ \\
\hline Grid: & $1000 \times 500$ grid points \\
\hline Grid resolution: & $2000 \mathrm{~m} \times 80 \mathrm{~m}$ \\
\hline Wave Perturbation: & $\Delta \mathrm{T}=\Delta \mathrm{T}_{0} * \cos \left(\mathrm{kx}+\mathrm{m}\left(\mathrm{z}-\mathrm{z}_{0}\right)\right), \mathrm{z}_{0}=10 \mathrm{~km}$ \\
\hline Gravity wave spectrum: & $\lambda_{\mathrm{X}}=100-1000 \mathrm{~km}, \lambda_{\mathrm{Z}}=1-10 \mathrm{~km}$ \\
\hline
\end{tabular}

The measurement geometry is depicted in Fig. 1. It shows a typical wave pattern propagating through the atmosphere. The lines of constant phase are tilted against the horizontal. During the occultation of the GPS satellite the ray path intersects the phase lines of the gravity wave and the receiver scans the vertical profile of the periodic temperature disturbance top down. The model domain where the temperature disturbance is calculated from the path delay of the GPS signal introduced by the simulated wave is indicated as the grey rectangle. Since a dry atmosphere is assumed, the lower boundary of the model is set to $10 \mathrm{~km}$. This satisfies also the condition that gravity waves are often generated at height ranges between $5 \mathrm{~km}$ and $10 \mathrm{~km}$ e.g. from the flow over high mountain ridges.

\section{The problem of detecting gravity waves by RO measurements}

Figure 2 illustrates the problem of the measurement geometry. When the GPS signal propagates perpendicular to the wave crests (arrow line from left to the right) the positive and negative phase variations cancel out the resulting path delay. In direction parallel to the wave crests (arrow line from bottom to the top of the panel) the detected signal shows maximum amplitude. The ratio of the detected temperature variation at the GPS receiver and the maximum of the wave vary between 0 and 1 depending on the horizontal view angle $\alpha$. Short scale waves can be "seen" in the derived temperature profiles or not. The retrieved temperature amplitude increases with $\sin \alpha$. 


\section{Viewing geometry}

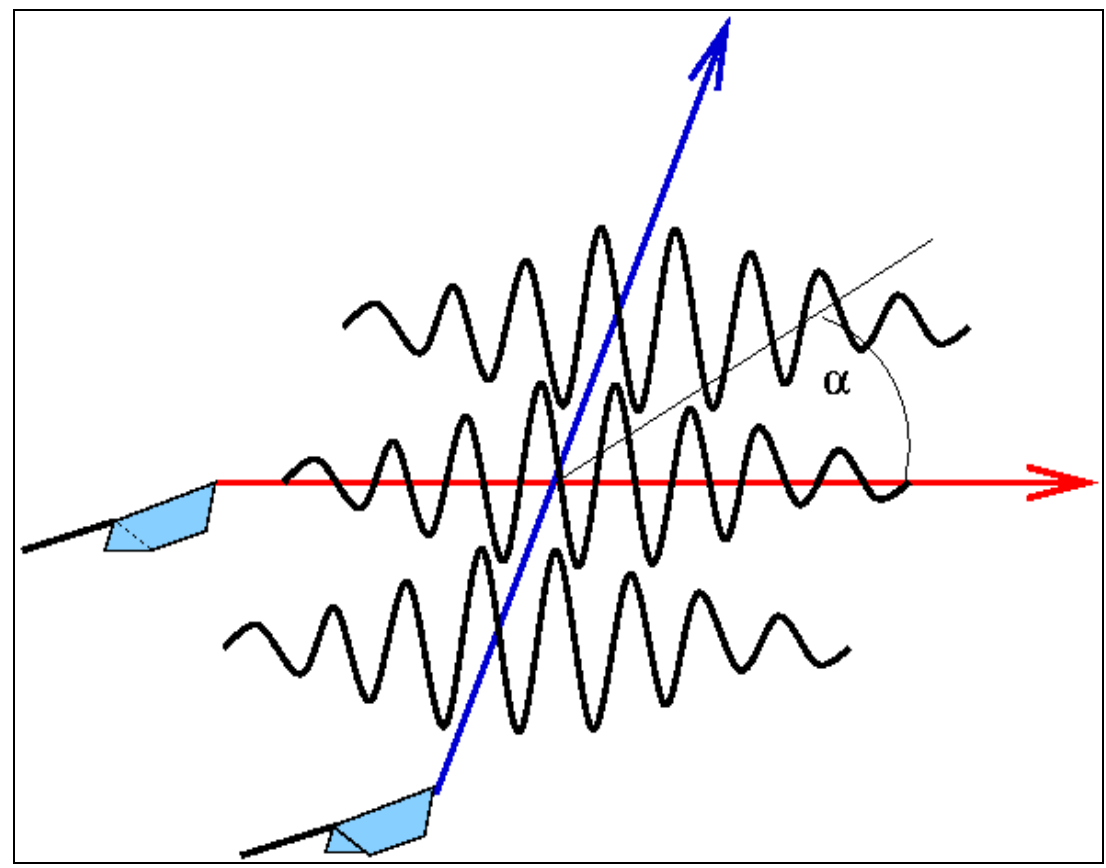

Figure 2: Viewing geometry of the LEO satellite through a plane gravity wave pattern.

\section{Gravity wave perturbation}

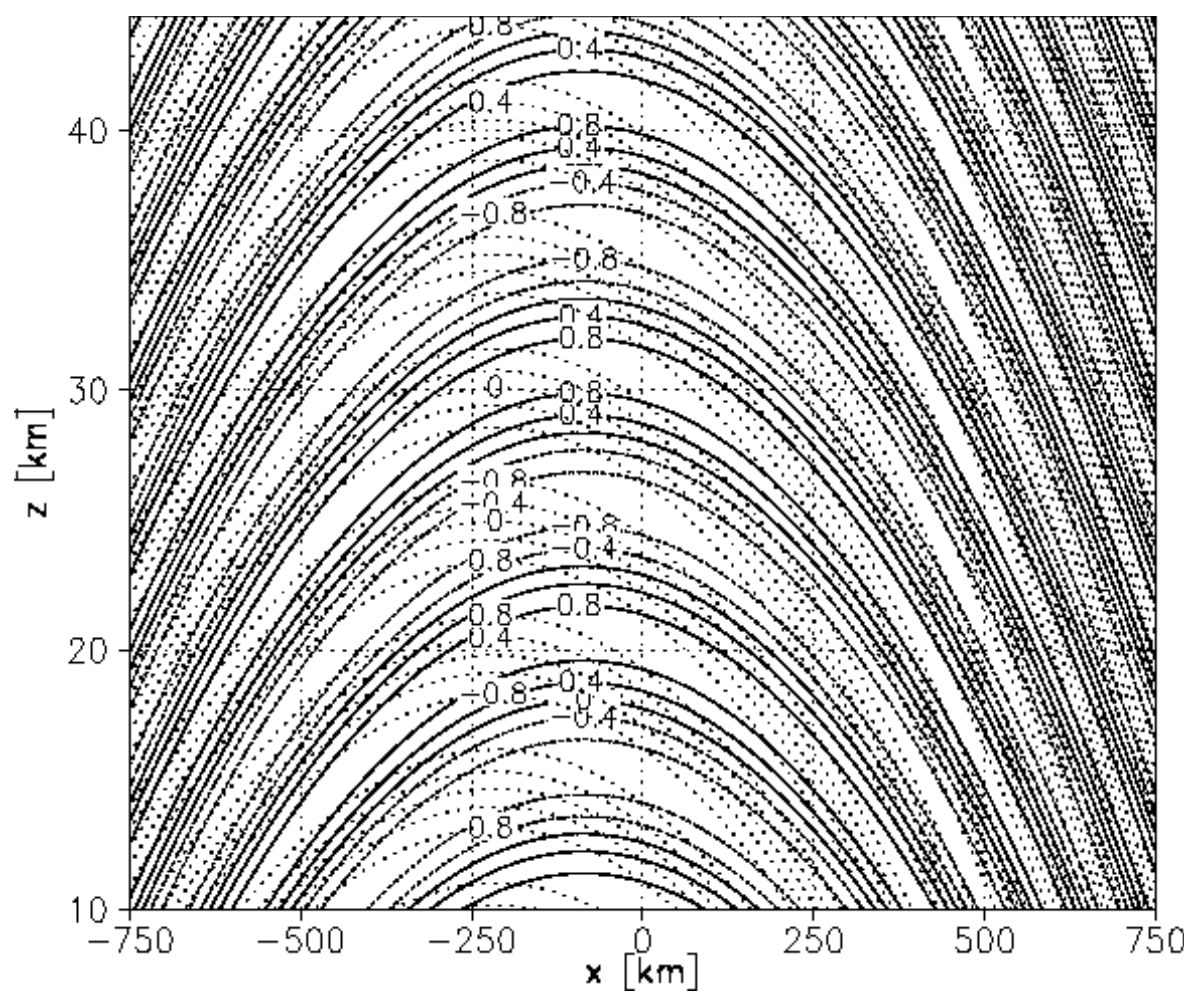

Figure 3: Lines of constant phase for gravity waves with a vertical wavelength of $10 \mathrm{~km}$ and horizontal wavelength of $1000 \mathrm{~km}$ (solid) and $400 \mathrm{~km}$ (dotted lines). The z-axis represents the geometric height at $x=0$. 
Fig. 3 shows an example of two simulated plane gravity waves of the type mentioned in the model description with a normalized constant amplitude $\mathrm{T}_{0}=1$. The vertical wavelength is in both cases $10 \mathrm{~km}$ and the horizontal wavelength $1000 \mathrm{~km}$ (solid lines) respectively $400 \mathrm{~km}$ (dotted lines). The shorter horizontal wavelength $\lambda_{X}$ is equivalent to a stronger tilt of the wave vector against the z-axis. This leads to a horizontal shift of the lines of constant phase with respect to $\mathrm{x}=0$. Ray bending and phase delay of the GPS signal are strongest at the maximum vertical gradient of the atmospheric refractive index at lines $\mathrm{dn} / \mathrm{dr}=0$ (Belloul and Hauchecorne, 1997). At this point the constant phase lines of the wave are tangent to the occultation ray that crosses the model domain horizontally. Therefore the shift of the phase lines in $x$ direction that corresponds to shorter $\lambda_{\mathrm{X}}$ leads to a horizontal shift of the detected temperature profile.

\section{Results}

\section{Simulated and derived temperature disturbances.}

To illustrate the influence of the horizontal and vertical wavelength, Figure 4 shows the normalized temperature perturbations of two gravity waves with different vertical wavelength of $1 \mathrm{~km}$ and $7 \mathrm{~km}$. The agreement of the derived (dashed line) and original temperature profile(solid line) shows, that even gravity waves with relative short horizontal wavelength of $200 \mathrm{~km}$ may be resolved correctly in amplitude and phase if the vertical tilt of the wave vector against the vertical is small, what is satisfied in case of the short vertical wavelength. In the case of the stronger vertical tilt (right panel) the derived temperature for the wave with a horizontal wavelength of $200 \mathrm{~km}$ (dashed line) undergoes a phase change by about 180 degrees and the amplitude decreases by $50 \%$. Good agreement of the retrieved gravity wave signal occurs for horizontal wavelength above $600 \mathrm{~km}$ (dotted line) where the retrieved amplitude is about $90 \%$ of the original and the phase shift is in the range of 10-20 degrees.
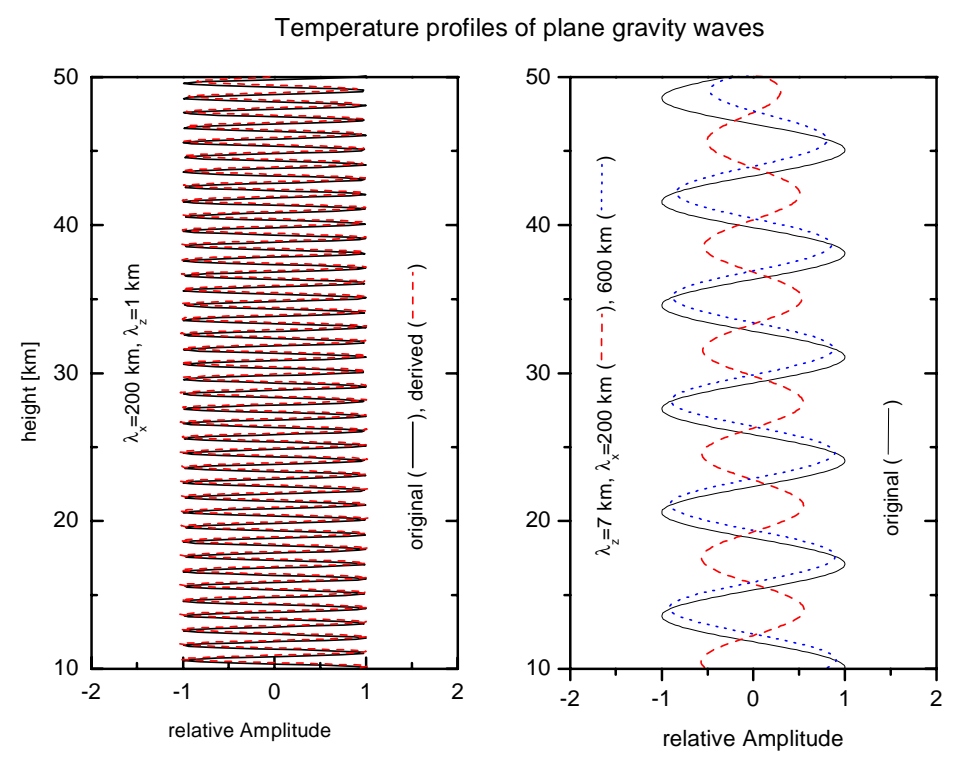

Figure 4: Original (solid line) and derived normalised temperature profiles (dashed line) for gravity waves with vertical wavelength of $1 \mathrm{~km}$ (left panel) and $7 \mathrm{~km}$ (right). The horizontal wavelength is $200 \mathrm{~km}$. The dotted line in the right panel indicates a horizontal wavelength of $600 \mathrm{~km}$ for the second case. 


\section{Visibility of plane gravity waves}

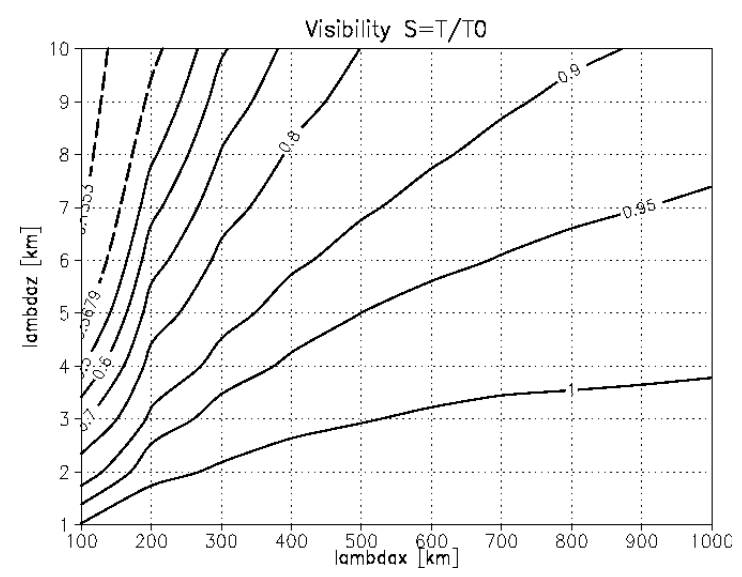

Figure 5: Visibility of plane gravity waves defined as Amplitude ratio between the retrieved and the original gravity wave temperature perturbation. The horizontal and vertical wavelength are in the range $\lambda_{x}=100-1000 \mathrm{~km}$ and $\lambda_{z}=1-10 \mathrm{~km}$.

Figure 5 shows a more general picture of the visibility of gravity waves in dependence from the horizontal and vertical wavelength than described for the single profiles above. Visibility is defined here as the ratio between the derived temperature amplitude and the original amplitude. The dashed lines indicate the range, where the visibility decreases to $1 / \mathrm{e}$ and $1 / \mathrm{e}^{2}$. The $90 \%$ level is approximately given by the linear connection of the points $\left(\lambda_{X}=100 \mathrm{~km}\right.$, $\left.\lambda_{\mathrm{Z}}=2 \mathrm{~km}\right)$ and $\left(\lambda_{\mathrm{X}}=1000 \mathrm{~km}, \lambda_{\mathrm{Z}}=10 \mathrm{~km}\right)$. Comparing the areas on the right and the left more than $50 \%$ of the waves of the spectrum are retrieved with a higher amplitude. The isolines show, that below the $90 \%$ level the visibility is nearly directly represented by the aspect ratio, which determines the ratio of the horizontal to the vertical wavelength. It is found, that waves with an aspect ratio above $200 \mathrm{~km} / 5 \mathrm{~km}$ are visible in the 1/e sense and more than $90 \%$ of the retrieved temperature amplitudes are above the $60 \%$ level.

All the results hitherto described assume, that the satellite views perpendicular to the wave crests. The same derived temperature amplitudes may be obtained for even shorter horizontal wavelength, if the view angle between the line of sight and the horizontal k vector of the wave labelled $\alpha$ in Fig. 2 is larger. Therefore the badest case of geometry has been considered for plane gravity waves. To estimate this effect, the visibility in dependency on the vertical wavelength and the view angle is considered for a relative short and a more large scale horizontal wavelength.

Figure 6 shows the visibility (left panels) and the phase difference (right panels) between the derived and the original gravity wave perturbation subject to the horizontal angle between the line of sight and the horizontal k-vector of the wave for horizontal wavelengths of $200 \mathrm{~km}$ and $500 \mathrm{~km}$ respectively. As already mentioned in the discussion of the measurement geometry (vis. Fig. 2) the derived temperature signal increases to the amplitude of the original wave perturbation while turning the occultation ray via the infinitely expanded lines of constant phase following the sinus law. Also the phase lag changes with increasing view angle. For short horizontal wavelengths as shown for $200 \mathrm{~km}$ in the upper right panel and vertical wavelengths above $7 \mathrm{~km}$ the phase shift cycles through a maximum and becomes smaller than 10 degrees at view angles above 80 degrees. At the phase jump the contour lines are slightly inhomogenious. 

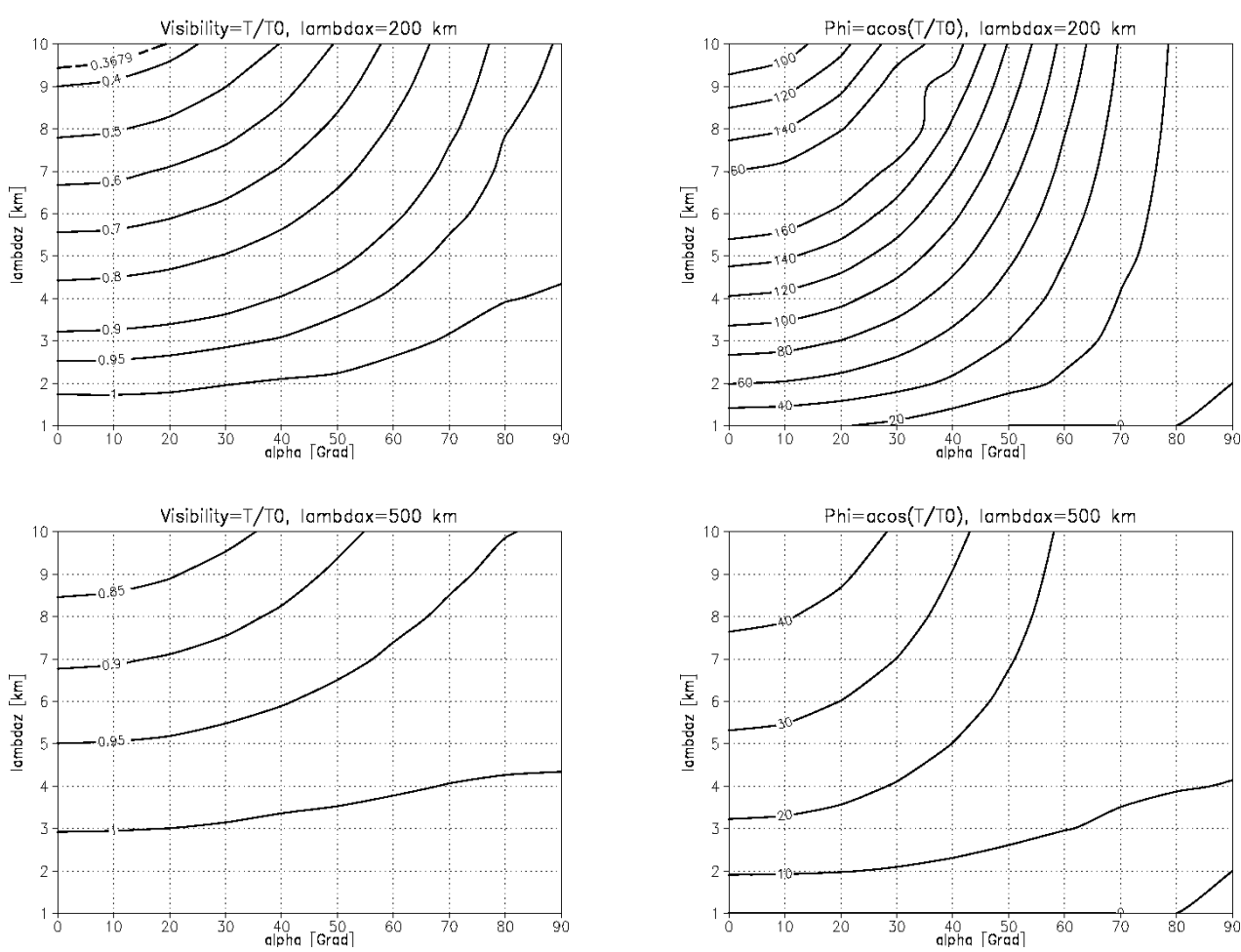

Figure 6: Visibility of plane gravity waves (left panels) and phase difference (right panels) between the derived and the original wave subject to the horizontal view angle between the line of sight and the horizontal $k$-vector of wave. The respective horizontal wavelengths are $200 \mathrm{~km}$ and $500 \mathrm{~km}$.

For a horizontal wavelength of $500 \mathrm{~km}$ (lower right panel) the phase shift is about 45 degrees in the worst case, when the view is perpendicular through the wave crests and the vertical wavelength is $10 \mathrm{~km}$. Since the phase shift vanishes with increasing view angle, waves with horizontal wavelength above $500 \mathrm{~km}$ are resolved with a vertical phase shift below $\lambda / 8$.

Summarising the effect it must be stated that it is difficult to attribute gravity wave patterns obtained from single radio occultation measurements to the original disturbance since multiple combinations of the geometric parameters lead to a similar result. Neglecting the problems that arise from the idealisation of the atmospheric conditions and the specific wave properties in the case described here additional information is necessary to specify the orientation of the wave. An interesting case would occur if multiple satellites measure near the same tangent point. Then their different view geometry can be used to specify the orientation of idealised wave types.

\section{Conclusions}

Periodic perturbations of the atmospheric density, derived from radio occultation measurements, depend on the geometrical wave parameters and the horizontal view angle between the occultation ray and the wave. The tilt of the lines of constant phase increasing with larger vertical wavelength lead to a reduction of the amplitude and shift in the phase in the retrieved temperature profile. For the simulated gravity wave spectrum more than $90 \%$ of the retrieved temperatures are above the $60 \%$ Amplitude level and more than the half of the derived amplitudes are above $90 \%$. It turns out that gravity waves with an aspect ratio above $200 \mathrm{~km} / 5 \mathrm{~km}$ can be resolved by radio occultations. The future task is to find correction methods to improve the retrieved temperatures. Notwithstanding the idealisation of atmospheric conditions and the 
specific wave properties the exakt amplitude and phase of gravity waves can not be derived from single occultation measurements. Since one signal can be attributed to multiple combinations of wave amplitude and phase lag additional informations are necessary to identify the geometric parameters. Nevertheless, as reported earlier in Belloul and Hauchecorne (1997), increasing phase lag between the derived and original wave perturbation and the decrease of the observed wave amplitude occurs simultaneously. Therefore, the part of the spectrum, that is difficult to identify appears only weak and is small compared to the rest. Since the number of LEO satellites are supposed to increase significantly in the next decades additional information can be provided by multiple occultations near the same tangent point at time scales shorter than one wave period. Besides the interest at gravity waves itself errors of the retrieved temperatures make correction methods for gravity waves desirable.

\section{Acknowledgements}

This study was supported by the Deutsche Forschungsgesellschaft under grant JA 836-4/1 and by INTAS under grant 991-1186. The project is imbedded in the CHAMP mission leaded by the GFZ Potsdam.

\section{References}

Fjeldbo, G. and V.R. Eshleman, 1965: The bistatic radar occultation method for the study of planetary atmospheres. J. Geophys. Res.13, 3217-3225.

Belloul, M.B., and A. Hauchecorne, 1997: Effect of periodic horizontal gradients on the retrieval of atmospheric profiles from occultation measurements. Radio Sci., 32, 469-478.

Hocke, K., 1997: Inversion of GPS meteorology data. Ann. Geophys. 15, 443-450.

Kursinski, E.R., G.A. Hajj, J.T. Schofield, R.P. Linfield, and K.R. Hardy, 1997: Observing earth's atmosphere with radio occultation measurements using the global positioning system. J. Geophys. Res. 102, 23,429-23,465.

Preusse, P., A. Dörnbrack, S.D. Eckermann, M. Riese, B. Schaeler, J.T. Bacmeister, D. Broutman, and K.U. Grossmann, 2001: Space based measurements of stratospheric mountain waves by CRISTA. 1. Sensitivity, analysis method and a case study. J. Geophys. Res., accepted.

Tsuda, T., M. Nishida, C. Rocken, and R.H. Ware, 2000: A global morphology of gravity wave activity in the stratosphere revealed by the GPS occultation data (GPS/MET). $J$. Geophys. Res., 105, 7257-7273.

\section{Address of the authors}

Martin Lange, Ch. Jacobi

Institut für Meteorologie Stephanstrasse 3, 04103 Leipzig.

email: mlange@uni-leipzig.de, jacobi@uni-leipzig. 